\title{
MENCARI FILOSOFI DI DUNIA KONTEMPORER DAN DI LINGKUNGAN AKADEMIS: SEBUAH OPINI
}

\author{
Dodi Sukmayadi (dodisy@ut.ac.id) \\ Universitas Terbuka
}

\begin{abstract}
This paper posits an opinion that the state of philosophy in contemporary world including in academic milieu is quiet unsatisfying in terms of how it is formulated and perceived. Though only lightly touched here and there, similar situation happens in Indonesia. Philosophy has been notoriously accused of corrupting young generations, of continuously irritating establishments, or at best leaves the world unchanged. Con-sidering that even music, for example, which satisfies only a few human sense, could have such enormous effect to human life, philosophy which claims to cover all traces of human existence could basically do something much much more, rather than simply uninfluencial or harming humanity. By elucidating initial and a little further meaning of philosophy, this paper try to build a foundation for such claim. In between such elucidation, it is briefly mentioned certain reasons why philosophy has been, is and will exist as long as human being exist. All in all, however, this article is only a beginning or at least the first part to explain the existensial nature of philosophy. A further article is needed to expound that.
\end{abstract}

Keywords: academics, contemporary, opinion, philosophy

Artikel ini mencoba memberi pengayaan pemahaman tentang filosofi sebagai sesuatu yang radikal (radix = akar) untuk dipahami tidak hanya untuk suatu masa tertentu. Setelah Nietzsche, filosofi perlu dipahami secara lintas jaman dan lintas ilmu,selain harus dipahami bagaimana filosofi dan masyarakat saling mengisi dan saling mempengaruhi. Filosofi, sejarah dan situasi kontemporer jalin-menjalin menjadi suatu kesatuan yang harus dipahami secara terpadu. Sepanjang sejarah yang kita ketahui, pemikiran tentang sains melahirkan, mengubah arah serta memberi warna perjalanan filosofi atau tradisi spiritual, selain juga mempengaruhi tradisi teknis/teknologi.

Kemudian, di dunia kontemporer kiranya ucapan Russel (1957) berikut masih tepat. Beliau menyatakan sains fisikal (fisika, kimia, biologi) mendominasi pemikiran filosofi atau tradisi spiritual, dan baru setelah itu sains behavioral (psikologi) yang mungkin akan mendominasi. Akan tetapi, secara umum, sains mungkin memberi dampak sangat besar bagi kehidupan manusia, termasuk ke dalam hal-hal mendasar manusia, seperti keyakinan relijiusnya.

"Sains paling berpengaruh sampai saat ini adalah fisika dan kimia; biologi baru akan menyaingi keduanya. Tapi, dalam waktu dekat ini, psikologi dan terutama psikologi massa akan dikenali sebagai sains paling penting bagi kesejahteraan manusia" (Russell, 1957: 394).

"Temuan-temuan ilmiah (seperti bom atom) membuat ilmuwan seperti seorang ahli magis dan enfant terrible masyarakat modern. Saran-sarannya yang sederhana dan rendah hati (atau justru sebenarnya dengan tinggi hati atau mungkin tanpa hati?) dapat 
mengusir wabah penyakit atau mempertanyakan kajian-kajian filosofi, petunjukpetunjuknya menentukan hidup atau mati, kekayaan atau kemiskinan pada berjuta-juta orang, persamaan-persamaannya yang profetik misterius mengatur arahnya nasib" (Bruun dalam Synder, 1955: 147).

Jadi, sekali pun Socrates di jaman Yunani kuno dulu sudah berupaya mengubah arah filosofi dari yang memfokuskan pada alam (Vico-an God made universe) ke yang memfokuskan pada manusia (Vico-an human made universe), rupanya upaya tersebut belum banyak berhasil. Artikel ini dari sudut pandang dunia modern mencoba untuk menjelaskan konstelasi makna dan bidang kajian filosofi (ontologi), senyampang diulas bagaimana filosofi lahir dan berkembang (epistemologi) dan diulas kegunaan filosofi (aksiologi). Setelah itu, diulas sekelumit implikasinya pada pendidikan filosofi di Indonesia.

Terdapat dua kata kunci dalam judul makalah ini, yaitu kata Sebuah Opini dan kata Mencari. Kata Sebuah Opini dimaksudkan bahwa dalam makalah ini diurai berbagai pandangan tentang filosofi yang (mungkin) tidak lazim di temui dalam literatur tentang filosofi di Indonesia. Secara ringkas dengan meminjam kata-kata Frankena (1982), makalah in berupaya untuk melakukan penyederhanaan dan penekanan di sana sini yang konon memerlukan lebih banyak sumberdaya dan keberanian dibanding dengan semata mengeritik dan merumitkan penyajian. Dengan ilustrasi, penyederhanaan dan penekanan seperti itu ibarat yang dikatakan Nietzsche dengan berjalan di daerah berbukit yang harus loncat dari satu puncak bukit ke puncak bukit berikutnya agar segera sampai ke tujuan, "Di daerah berbukit-bukit, jalan terpendek adalah melangkah dari satu puncak ke puncak lainnya. Namun untuk itu kita harus mempunyai kaki yang panjang" (Nietzsche, 1977: 16, 33). Ungkapan Nietzsche tersebut dapat saja kita terapkan pada berbagai bidang kehidupan lainnya, seperti: Di kehidupan yang Hobbse-ian short, brutish and nasty, jalan terpendek adalah dari Goetheian keabadian satu ke keabadian lainnya, dari Gus Dur-ian makam keramat satu ke makam keramat lainnya, dari gedung pencakar langit satu ke gedung pencakar langit lainnya layaknya selebiritis dan eksekutif abad modern, dari satu ibadah ke ibadah lainnya, dari satu mimpi ke mimpi lainnya, dari satu pemikiran komprehensif ke pemikiran komprehensif lainnya. Namun, untuk itu, kita harus mempunyai pemahaman/konsep imajinatif, komprehensif dan mendasar. Atau bahkan mempunyai keinginan "Untuk menyelesaikan segala sesuatu dengan satu langkah, dengan satu kata, Ahad, Ahad, Ahad. Jadi! Maka jadilah. Dengan al-qur'an! Dalam kata-kata Asyed Muhammad Al-Naquib AlAttas (yang diterjemahkan Bagir dan yang disunting Rachmat, 1984: 43), 'Al-Qur'an -sebuah buku besar yang terbuka dan setiap rincian di dalamnya meliputi cakrawala yang terjauh maupun diri kita sendiri- adalah seperti sebuah kata... yang berbicara pada manusia tentang siapa pengarangnya".

Selanjutnya, kata Mencari dalam judul dimaksudkan bahwa filosofi yang selama ini ditemui di dunia kontemporer Indonesia dan khususnya di dunia akademisnya dirasakan tidak lagi sesuai dengan tuntunan jaman. Orang dan akademisi tertentu cenderung menganggap filosofi sebagai kendala atau bahkan sebagai bahaya bagi kelangsungan kehidupan, seakan gaung ucapan Protagoras dari Yunani kuno tidak pernah berhenti didengar orang, terdapat kekuatiran yang kerap tidak disadari bahwa bernalar kritis akan menimbulkan anarki. Kekuatiran tersebut membuat para filosof tertentu bersembunyi di balik tabir pikir sesat dan kabur ... . Protagoras tidak tahu apakah dewa benar ada, tapi ia berpendapat dewa harus disembah. Protagoras mengatakan filosofi tidak mempunyai daya pencerahan (bagi kebanyakan orang) dan kelestarian sosial harus disandarkan pada kebodohan mereka dan pada kesediaan mereka mempercayai apa saja yang diajarkan pada mereka (Russel, 1988). Filosofi dianggap hanya mempersulit keadaan yang sudah sulit, dianggap 
sama sekali tidak memberikan pencerahan dan/atau solusi alternatif. Padahal tentulah keberadaan filosofi semestinya menjadi fondasi bagi kehidupan, terlebih lagi bagi dunia akademis.

... "Filosofi ruang lingkupnya komprehensif [meliput] semua jenis pengalaman manusia...di masa lalu, masa sekarang atau masa depan, aktual atau ideal, nyata atau mungkin (possible)...ultim atau bukan... Fungsi filosofi adalah interpretasi makna: simbolis, empiris, estetis, sinoetis, etis [dan] historis [serta relijius]. Jadi, makna yang diekspresikan dalam filosofi adalah makna dari makna-makna atau dapat kita namakan meta-makna" (Phenix, 1964, 253).

Jadi, dengan kata Mencari, makalah ini memfokuskan pada suatu rumusan tentang filosofi yang dianggap sesuai dengan jaman yang sedang kita jalani ini. Kemudian, juga diulas kemungkinan relasi, peran dan implikasinya bagi lingkungan akademis,khususnya di Indonesia.

\section{Konstelasi Makna Awal Filosofi}

Makna awal filosofi dapat kita selami dengan memperhatikan Gambar 1.
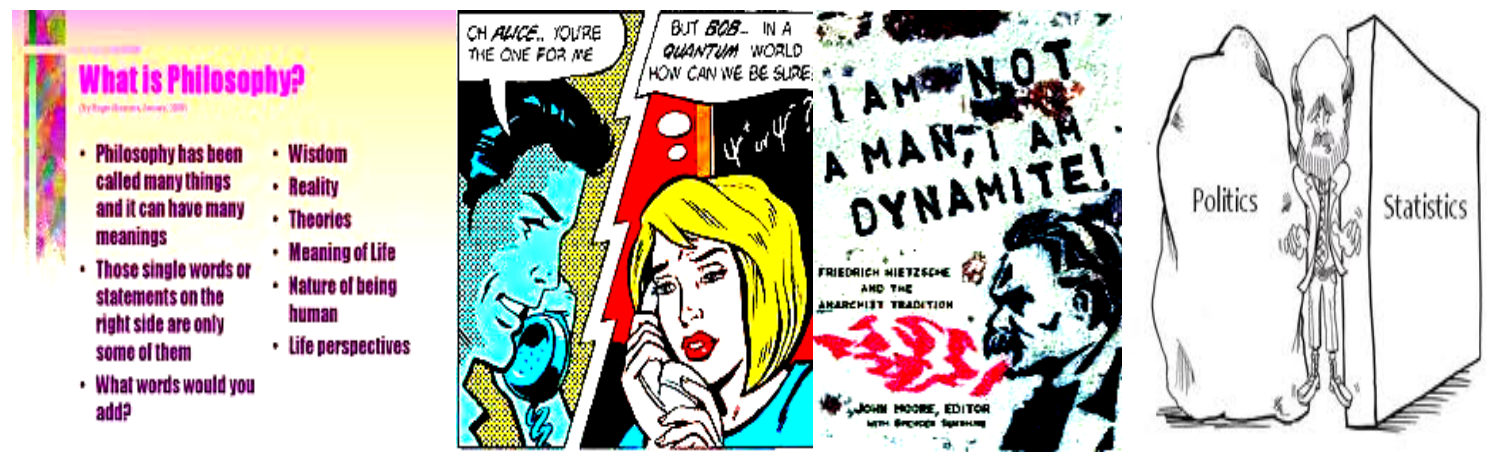

Sumber: htt://www.google.co.id/images?hl=id\&biw=1179\&bih=563\&gbv=2\&tbs= isch\%3A1\&sa=1\&q=philosophy\&btn $\mathrm{G}=$ Telusuri\&aq=f\&aqi=g2\&aql=\&oq=, http://www.google.co.id/images?hl=id\&biw=1179\&bih=563\&gbv=2\&tbs=isch\%3A1\&sa=1\&q=fisika +kuantum\&btnG=Telusuri\&aq=f\&aqi $=g 1 \& a q \mid=\& o q=$ http://www. google.co.id/images?hl=id\&client=firefox-a\&rls=org.mozilla\%3Aen GB\%3Aofficial\&biw=1152\&bih=674\&gbv=2\&tbm=isch\&sa=1\&q=accountability\&aq=4\&aqi=g10\&a $\mathrm{q} \mid=\& \mathrm{oq}=\mathrm{account}$

\section{Gambar. 1. Ilustrasi makna awal filosofi}

Empat frame pada Gambar 1 memberi pengertian awal (secara ontologis, epistemologis dan aksiologis) kepada kita tentang apa yang dinamakan dengan filosofi. Frame pertama menyatakan bahwa filosofi dialiaskan dan bermakna beragam bagi tiap orang. Filosofi mungkin bermakna kebijakan, realitas, teori, makna kehidupan, hakekat manusia atau perspektif kehidupan. Dalam pemikiran Michel Foucault, filosofi yang beragam makna tersebut niscaya ibarat kehidupan dunia akademis yang dengan baik digambarkan frame kedua. Dunia kuantum mengenal ketidak-pastian Heisenberg. Jadi, ketika seseorang misalnya mengatakan "Engkaulah satu-satunya pujaan hatiku", maka jawab yang tepat (dalam hati setidaknya) adalah "Di dunia kuantum, mana bisa kita berbicara serba pasti". 
Dunia serba pasti bagi Foucault niscaya adalah dunia polisi, tentara dan birokrat. Mereka senang berbicara hal faktual 'pasif dan miskin', seperti misalnya kalimat (bukan frasa!) 'Pekerjaan selesai'. Kalimat 'pasif' itu 'miskin' makna. Dengan kalimat itu, mereka tidak peduli: oleh siapa pekerjaan diselesaikan, bagaimana proses dan hasil pekerjaan itu, dikerjakan dengan cepat, lambat atau bagaimana, hasilnya baik buruk atau bagaimana. Dengan kalimat-kalimat seperti itu kiranya skandal atau korupsi seberat apa pun dapat di-'peti-es'-kan. Sepertinya fungsi mereka (polisi, tentara dan birokrat serta kalimat-kalimat yang diucapkannya) adalah untuk korupsi makna (yang berkembang di dunia akademis) sebagai bagian -atau awal dan sekaligus kulminasi- dari korupsikorupsi lainnya. Mereka itu seperti barbar yang omisi (memotong, mengurangi) dan komisi (menambah) makna di sana-sini.

Dunia polisi, tentara dan birokrat adalah dunia yang bagi Bernard Shaw niscaya dikatakan sebagai dunia penguasa dunia yang bergelimang darah dan air mata pilu, dunia yang akan runtuh di depan matanya atau di masa hidupnya sendiri, sekali pun telah diperjuangkan dengan mati-matian dalam seumur hidupnya. Dalam frame 4 Gambar 1, dunia diibaratkan politik yang selalu menghimpit manusia melawan statistik (realita!). Dunia mereka berbeda dengan alam akademis Einsteinian alam yang hanya akan runtuh di kala kiamat nanti yang bergelimang kebenaran dan air mata bahagia: bahagia karena sains mencerahkan pemikiran dan kehidupan manusia.

Penyalahgunaannya saja yang membuat sains menjadi terdakwa untuk berbagai keruwetan dunia modern. Nietzsche salah alamat ketika mengatakan biang penyakit modern itu Socrates yang dipersepsinya sebagai bapak yang mengajarkan untuk mempertanyakan segala sesuatu. Mempertanyakan segala sesuatu (curiosity) adalah dasar keberadaan atau bahkan kewajiban manusia. Menurut Aristoteles, tidak menjelaskan segala sesuatu sama saja dengan tidak menjelaskan apa-apa. Manusia selalu ingin menjelaskan segala sesuatu. Namun, menjelaskan segala sesuatu adalah candu, jika penjelasan itu disediakan selain oleh diri sendiri dan/atau tanpa empirisme. Kondisi menerima penjelasan 'teoritis' tentang segala sesuatu selain oleh dirinya sendiri membuat orang terbius, hanya 'nrimo' saja, dan tidak menuntun ke (becoming) tanggungjawab dan kedewasaan, ke 'being'. Dan kondisi semacam itu pulalah kiranya yang membuat Adam memberontak [seperti Camus, 'Aku memberontak, maka aku ada'] dan menghendaki turun dari sorga ke bumi (Shariati, 1995). Lebih dari itu, Allah meninggikan derajat orang yang berilmu' Menurut Socrates, hidup yang tidak teranalisis dan teruji tidak berharga untuk dijalani. Namun, pendapat Nietzsche tentu ada benarnya, yaitu ketika kita kebablasan mempertanyakan segala sesuatu.

Serangan Nietzsche kepada Socrates mungkin dilandasi professional jealousy -atau mungkin seperti sibling rivalry dalam arti pertikaian antar sesama filosof. Socrates mengingatkan masyarakat agar filosofi jangan hanya sebatas filosofi tentang alam saja. Filosofi juga harus mengenai manusia dan kemanusiaan seperti kita lihat Einstein dari sisi pandangan Bernard Shaw. Socrates nampak mengubah arah filosofi dari tentang alam menjadi tentang manusia, tentang dunia. Atau, jika kita gunakan istilah Vico, dari filosofi tentang alam buatan Tuhan (God made universe), ke dunia buatan manusia (human made universe). Alam serba teratur dan dengan naïf dianggap benda mati, sehingga dipersepsi paling mudah untuk dipelajari. Pelajari yang mudah dulu, baru pelajari hal yang sulit seperti kehidupan. Perhatikan saja, misalnya, orang modern yang banyak belajar dari benda-benda mati yang terdapat dalam museum, insektarium, herbarium, dan lain sebagainya.

Lebih dari itu, begitu pula kiranya logika atau penjelasan mengapa filosofi tentang alam lahir lebih dulu dari filosofi tentang manusia (di tangan Socrates). Logika semacam itu masuk akal, walaupun tentu bukan satu-satunya logika yang dapat di terima. Logika Socrates - dan logika Konfusius di belahan bumi lain serta mungkin logika di dunia muslim- nampak mempertanyakan: 
mengapa mesti mempelajari sesuatu yang mati dan jauh dari kehidupan kita? Sudahkah kita memahami hidup kita sendiri? Sudah bosankah mempelajari hidup kita sendiri, sehingga kita harus mempelajari benda mati atau benda yang sekurang-kurangnya jauh dari kehidupan?

Akhirnya, logika mana sebenarnya yang harus kita terima: logika filosofi alam atau logika filosofi kemanusiaan? Mungkinkah dua logika ini pula yang sekurang-kurangnya sejak abad 17 menumbuhkan apa yang kita kenal sebagai dua tradisi filosofi (keilmuan): tradisi analisis AngloSaxon dan tradisi humanis Kontinental, atau tradisi pencerahan (enlightenment) dan dan tradisi romantisisme yang diantaranya tergambar dengan debat tradisi sains dan budaya seperti terlihat dari kutipan berikut?

"Debat paling terkenal tentang teori sains modern berlangsung pada tahun 1860 ketika Bishop Wilberforce berdebat dengan Thomas Henry Huxley (1825-1895). Sang bishop menyimpulkan serangannya pada teori evolusi dengan menanyakan leluhur monyet Huxley itu dari garis ayah atau dari garis ibu... [Huxley menjawab], "Jika saya ditanya apakah saya memilih leluhur monyet atau leluhur yang sangat berbakat dan berpengaruh, tapi menggunakan kelebihannya itu untuk mengolok-olok diskusi sains, saya tidak ragu pilihan saya tentu adalah leluhur monyet"... Sulit menemukan dua orang yang demikian kontras latar belakang pendidikannya seperti Wilberforce dan Huxley. Wilberforce dididik secara klasik di Oxford. Pengetahuannya tentang Yunani dan Latin teratasi oleh ketidak-tahuannya tentang sains. Huxley tidak pernah mengalami sekolah formal dan secara otodidak berpengahuan luas dalam sains dan sastra. Melihat ke belakang, kita sekarang cenderung memilih Huxley sebagai tokoh budaya dan Wilberforce sebagai kaum filistin (barbar!)" (Gardner, 1957: 126-7).

Atau, sebenarnya kedua logika tersebut (logika filosofi alam atau logika filosofi kemanusiaan), terkait dengan persoalan ontologis dan epistemologis keilmuan, yang jika tidak terlalu bermakna diurai, maka keduanya tidak terlalu banyak berguna untuk menuntut energi besar kita untuk mempelajarinya? Bukankah dari sisi aksiologis, kita tidak melihat kedua logika telah dapat menghasilkan suatu kebijakan yang menyejukan kemanusiaan? Atau, dengan kata lain, kita tidak dapat lepas dari logika Hume, "pengetahuan - seberapa banyaknyapun yang kita punyai- tidak akan menuntun ke keyakinan" (seperti kita berada di sumber air namun kita tidak mau minum, jika kita tidak menginginkannya). Dan jika 'keyakinan' saja tidak dapat kita capai, bagaimana dengan kebijakan, kesejahteraan dan segenap cita-cita mulia manusia lainnya? Mungkin saja Russell (1957: 394) benar ketika mengatakan "perlu kejeniusan untuk menemukan metode ilmiah, namun untuk penggunaannya cukup oleh orang yang berbakat saja". Tapi, apa sebenarnya metode ilmiah tersebut dan bagaimana penggunaannya?

\section{Refleksi atas Keberadaan dan Kegunaan Filosofi di Lingkungan Akademis}

Sebagai disiplin yang disebut dengan berbagai nama seperti kebijakan, realitas, teori, makna kehidupan, hakekat manusia atau perspektif kehidupan tentulah filosofi merupakan suatu disiplin pemikiran yang (paling) reflektif. Reflektif dalam arti setiap langkah pemikiran dan tulisan harus benar-benar konsisten, antara pemikiran satu dengan lainnya, selain juga konsisten dengan kenyataan di dunia luar dan di dalam diri penulisnya. Jadi, jika kita cermati uraian tentang makna awal filosofi, sebenarnya kita mempunyai pertanyaan-pertanyaan besar yang harus kita jawab. Tiga pertanyaan diantaranya ialah: (1) Dalam hal apa dan bagaimana uraian tersebut berbicara tentang 
sisi ontologis, epistemologis dan aksiologis filosofi? (2) Dalam hal apa dan untuk apa perspektif lain seperti perspektif relijius- diperlukan, ketika sains dan filosofi (sains) tidak dapat memenuhi kebutuhan (spiritual mendasar) manusia? (3) Adakah dalam uraian tersebut nuansa dunia dan nuansa alam? Dalam sub-bab ini, diurai dulu sketsa jawaban untuk pertanyaan ke-3, sedangkan pertanyaan ke-1 dan ke-2 diurai dalam sub bab berikutnya.

Nuansa alam mudah kita identifikasi: uraian tentang makna awal filosofi berbicara tentang sesuatu yang abadi, sesuatu yang dari jaman ke jaman relatif tidak berubah, tentang hakekat yang baik dan dengan demikian selalu baru (bukan sesuatu yang baru yang belum tentu baik). Menurut Durant (1966), kita tidak perlu filosofi baru; kita hanya perlu keberanian untuk mempraktekkan filosofi tertua dan terbaik. Nuansa dunia uraian sekalipun kental sulit kita identifikasi. Mungkin karena terlalu sering dan dalamnya kita berada di dalamnya. Apa gerangan nuansa dunia dalam makalah ini? Anda mungkin perlu menggalinya dengan arkeologi (lapis demi lapis ilmu) dan genealogi (kekerabatan berbagai ilmu)nya Foucault, sehingga kita dapat memahami pemikiran gurunya Foucault, Nietzsche, yang menyatakan di dunia akademis tidak mungkin ditemukan kebenaran radikal (dalam arti seperti diurai di awal tulisan). Ucapan Nietzsche bahwa kebenaran radikal tidak mungkin ditemukan di dunia akademik. Suatu yang dapat dikatakan sebagai bukti dari ucapan Nietzsche tersebut di negeri kita adalah -entah dengan bijak atau dengan bodoh- (hampir?) semua mata kuliah dan/atau program studi dan jurusan filosofi ditutup. Mungkinkah hal tersebut adalah semata berkaitan dengan keadaan pada saat itu yang bernuansa otoriter, ideologi tunggal, baik di pusat pemerintah maupun di daerahdaerah? Atau, memang karakter filosofi tidak dapat hidup di dunia akademis, terlebih lagi di jaman yang menuntut serba cepat dan materialistis yang dari saat itu sampai sekarang mendominasi kehidupan kita?

Kita sebut petunjuk untuk mencari satu-dua nuansa dunia dalam uraian tentang makna awal filosofi tersebut. Satu-dua petunjuk tersebut adalah berupa pertanyaan: Apakah anda perhatikan kepada siapa uraian ditujukan? Bagaimana tulisan ini secara fisikal dan sekuen materi disajikan? Sumber-sumber mana saja yang digunakan untuk menulis uraian dimaksud, dan seterusnya. Dari jawaban atas pertanyaan tersebut niscaya anda akan menyadari bahwa kesemuanya harus mengikuti suatu aturan baku yang sering membeku-kan - dan dengan demikian merongrong kebenaran, bukannya menuntun kepada kreativitas pencarian kebenaran.

Suatu jawaban yang dalam dunia kontemporer berupaya membebaskan diri dari kebekuan tersebut adalah jawaban yang mengacu pada kata-kata Jacques Derrida bahwa filosofi itu semata tulisan, sama halnya dengan tulisan tentang puisi, cerpen, artikel, dan lain-lain. Tulisan tentang filosofi tidak semata mencari kebenaran, tulisan tentang seni tidak semata untuk mencari hiburan.Tulisan tentang filosofi dan tulisan tentang seni, menurut Derrida, mungkin sama-sama mencari kebenaran, hanya saja tataran kebenarannya saja yang berbeda. Keduanya juga mungkin sama-sama bertujuan untuk menghibur. Tentu saja, cara dan makna hiburannya berbeda. Namun, kiranya jawaban tersebut juga tidak cukup membebaskan, karena bisa saja tidak cukup benar. Ucapan Derrida, semua tulisan itu -termasuk tulisan tentang filosofi- sama, mungkin juga harus mengakui 'hukum' Aldous Huxley, 'semua tulisan itu sama, hanya saja tulisan-tulisan tertentu jauh lebih sama dibanding dengan tulisan-tulisan lainnya'. Ke mana dan bagaimana kita mencari jawaban dapat diterima? Dan di balik pertanyaan itu, kita juga dihadapkan pada pertanyaan lebih mendasar: Benarkah filosofi adalah bidang yang selalu saja menemui pertanyaan seperti ini (yaitu tidak tahu persis ke mana dan bagaimana kita mencari jawaban, tidak tahu persis epistemologinya sendiri)? 
Jika epistemologinya saja susah dicari, tentulah ontologisnya juga akan jauh lebih sulit dicari. Oleh karena itu, dapatkah sisi ontologis dan epistomologis filosofi kita cari dan dekati dari sisi kegunaan atau aksiologisnya? Mengenai aksiologi filosofi bagi dunia tersebut, kita amati ada semacam folk wisdom bahwa dunia secara global nampak sedang merayakan abad-abad berakhirnya ideologi (the end of ideology). Dari kelompok ideologi yang ditandai dengan kata isme di belakangnya (nazisme, fasisme, sosialisme), hanya tinggal kapitalisme (dan feminisme) yang di sana sini masih disebut. Objek keilmuan tidak lagi sesuatu yang besar seperti masyarakat atau ilmu (dulu dipelajari dalam 'sosiologi', atau 'tatanan logis/ilmu tentang aspek sosial masyarakat'), tapi objek yang lebih kecil seperti komunitas, wanita, kultural, kritikal. Studi dalam bentuk seperti di sebut studi wanita (feminisme), studi kultural, studi kritikal, dan seterusnya.

Sejumlah pakar menamakan abad 20-21 sebagai abad reflektif, abad ketika pencapaian tinggi di dunia material mereka alami, namun tidak kunjung menuntun ke pencapaian tinggi di dunia spiritual. Tapi, reflektif juga mungkin saja diklaim bermakna makin demokratis, makin kurang otoriter dan makin toleran terhadap pemikiran orang lain. Padahal sebenarnya mungkin orang makin kehilangan pegangan hidup. Sisi kontradiktif tersebut terlihat pada 'makna' kutipan berikut. Kutipan tersebut di satu sisi merupakan sebuah testimoni tentang berbagai 'isme' yang bernuansa politis (tapi yang pengaruhnya pada dunia akademis tidak dapat diabaikan) adalah sebuah masa lalu saja, tapi di sisi lain betapa kultur kuat bangsa diperlukan untuk mengarahkan sains, tidak ke isme-isme sesat dimaksud, tapi ke arah isme yang lebih bertanggungjawab,

Berbagai ragam kegilaan - komunisme, nazisme, imperialisme..- adalah produk alami impak sains pada bangsa-bangsa yang kulturnya kuat sebelum sains mewarnainya (Russel, 1957: 193).

Mencari aksiologi secara lebih konseptual lagi, kita lihat, misalnya, frame 3 pada Gambar 1: Nietzsche adalah filosof yang mengaku dirinya bukan manusia, tapi sebuah dinamit. Seperti dinamit yang setelah meledak pecah berkeping-keping menjadi serpihan sampah, hidup Nietzsche ditandai oleh badai dalam secangkir kopi kehidupannya, kemudian ditandai oleh banyak waktu di akhir hidupnya yang dijalani di rumah sakit jiwa (the right man in the right place, bagi orang yang sinis kepadanya). Tapi, seperti dinamit juga, kata-katanya meledak-ledak, sehingga sedemikian banyak orang terpengaruh secara signifikan olehnya. Orang pun bertanya: Benarkah semua filosofi selama ini salah dan hanya Nietzsche yang benar dengan trans atau re-evaluation of all values-nya atau memang Nietzsche yang salah? Tidak ada filosof yang menimbulkan efek seperti itu, kecuali mungkin Plato yang menurut Whitehead, semua filosofi sebenarnya adalah semata catatan kaki buat Plato. Jika sebutir peluru saja yang menembak seorang pangeran, the right man in the wrong place, dapat menuntun ke Perang Dunia I, bagaimana pula efek sebuah dinamit? Nazi-nya Hitler, misalnya, mendewakan - dan dengan demikian mengkhianati- Nietzsche. Dengan demikian, apa arti filosofi bagi masyarakat? Kata Marx, tugas filosofi itu untuk mempelajari dunia, dan tugas kita adalah mengubah dunia. Perspektif Habermasian tentang philosophy with practical intents menyatakan kita perlu mempelajari dunia agar kita mampu mengubahnya. Sementara itu, filosofi, kata Wittgenstein, tidak menimbulkan apa-apa pada masyarakat (leave the world as it is).

Selain kasus Nietzsche, peristiwa dramatis tentu adalah ketika filosofi harus membuat Socrates dan Artistoteles dihukum mati oleh masyarakatnya. Socrates mati dengan minum racun, Aristoteles lari dari takdir tersebut karena dalam pandangannya, 'saya tidak akan membuat Athena berdosa untuk kedua kalinya'. Mengapa masyarakat demikian memandang filosofi dengan salah atau 
mungkin mengkhianati filosofi? Apakah hal itu karena dalam filosofi sendiri yang silih berganti mewarnai tiap jaman, hal yang terjadi adalah satu pengkhianatan demi pengkhianatan berikutnya? Kemudian, agar pengkhianatan itu tidak terlihat dramatis, kita ubah dan korupsi kata itu dengan kata 'tradisi'?

"[Menolak tradisi adalah jantung dari filosofi] Heidegger menolak filosofi Barat sambil pada waktu sama meneruskan tradisi itu sendiri. Rousseau... menolak filosofi tradisional dengan mencari titik Archimedian 'keadaan alami'. Kant mulai dengan kritik pada metafisika tradisional... Hegel mulai dengan mengritik Kant. Kierkegaard dan Marx menolak Hegel atas nama subjektivitas dan sains" (Solomon, 1988:153).

Dalam bahasa lebih halus, Foucault (Martin et. al., 1988) mengungkapkan bukan pengkhianatan filosofi demi filosofi, tapi pengkhianatan masyarakat pada filosofi pasca-Socrates.

"Dalam banyak kesempatan orang bertanya pada saya apa yang akan terjadi di masa depan dan meminta saya untuk memberi mereka petunjuk apa yang harus dilakukan. Kita tahu bahwa, bahkan dengan niat terbaik sekalipun, petunjuk-petunjuk seperti itu dapat menjadi alat atau instrumen opresi. Gagasan-gagasan Rosseau, seorang pecinta kebebasan, digunakan revolusi Perancis untuk menjadi alat opresi sosial. Marx akan sangat ketakutan oleh Stalinisme dan Leninisme" (Foucault, dalam Martin et. al., 1988:10).

Jadi, dengan perspektif Solomon dan Foucault tersebut, tidak heran jika disinggung di awal tulisan bahwa gaung Protagoras tidak berhenti di jamannya saja, "Protagoras mengatakan filosofi tidak mempunyai daya pencerahan (bagi kebanyakan orang) dan kelestarian sosial harus disandarkan pada kebodohan mereka dan pada kesediaan mereka mempercayai apa saja yang diajarkan pada mereka" (Russel, 1988: 90). Kemudian, di hadapan sedemikian banyak kendala yang dihadapi filosofi yang membuatnya seperti useful mistakes for wrong problems, mengapa pula masih saja ada orang yang dengan persisten tetap menulis tentang filosofi? Suatu alasannya ialah kita dibuai -atau mungkin diyakinkan- ucapan Santayana bahwa filosofi kaya visi. Santayana (Durant, 1966) mengatakan bahwa sekalipun filosofi lain selain dari yang diajukannya masih dapat dimungkinkan, suatu filosofi bukanlah suatu yang tidak emosional. Jika musik yang dapat penuh gairah semata karena memberi bentuk pada satu indera, seindah atau semengerikan apa sebuah visi yang kaya kandungan tatanan dan metode pada semua yang kita ketahui? Filosofi adalah sebuah visi yang kaya kandungan tatanan dan metode pada semua yang kita ketahui, pada semua yang kita inderai. Alasan lain yang lebih mendasar kiranya adalah keyakinan Foucault bahwa kita sebenarnya jauh bebas dari yang kita bayangkan sendiri, untuk menunjukkan, dalam ungkapan Shakespeare, bahwa bintang di langit lebih banyak dari yang dapat kita mimpikan!

"Apa yang anda bayangkan sehingga saya bersusah payah atau bersenang-senang menulis, apa yang anda pikirkan sehingga saya persisten dengan tugas saya" (Foucault dalam Danaher et. al. 2000: 1)... "Peran saya -meskipun istilah tersebut terlalu empatik- adalah memperlihatkan pada orang bahwa mereka lebih bebas [dalam hal tertentu atau lebih terkungkung dalam hal lainnya lagi] dari yang mereka sangka, bahwa yang diterima orang selama ini sebagai kebenaran dapat dikritik dan 
dihancurkan. Untuk mengubah sesuatu yang ada di pikiran orang - itulah peran seorang intelektual" (Foucault dalam Martin et. al., 1988:10).

\section{Konstelasi Makna Lanjut Filosofi}

Makna lebih lanjut dari filosofi secara sekilas dapat kita selami dengan memperhatikan Gambar.2.
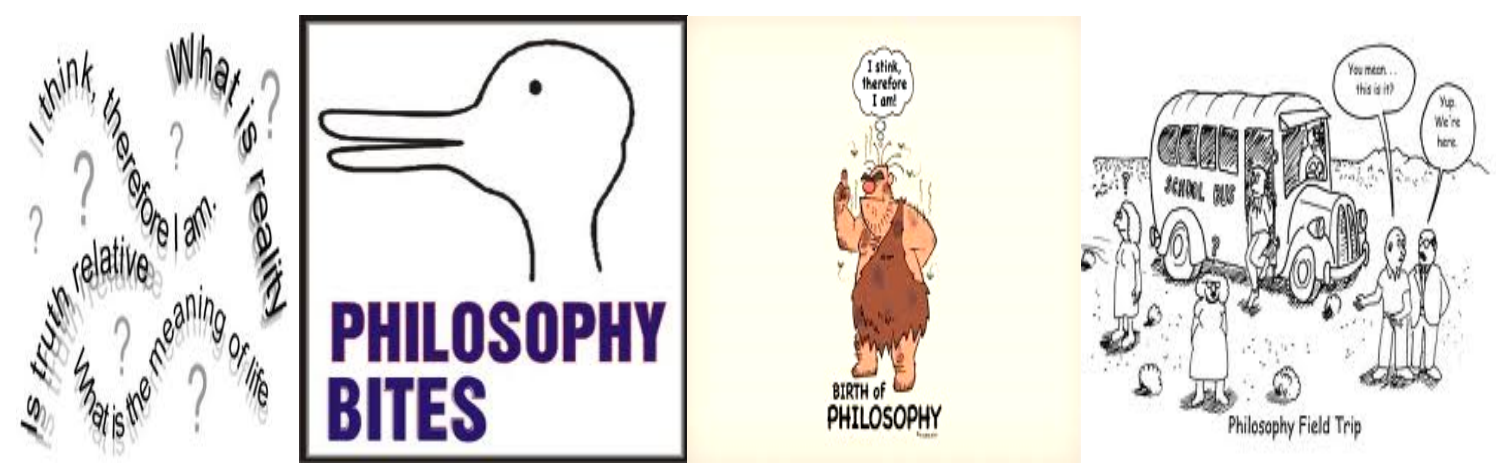

Sumber:http://www.google.co.id/images?hl=id\&biw=1179\&bih=563\&gbv=2\&tbs=isch\%3A1\&sa=1\&q=philosophy\&btnG=T elusuri\&aq=f\&aqi=g2\&aq|=\&oq=

Frame pertama Gambar 2 kurang-lebih menyatakan hal yang sama dengan yang dinyatakan pada frame pertama Gambar 1. Hanya saja rumusan tiga pertanyaan (Apa yang disebut realitas itu? Apa makna kehidupan? Apakah kebenaran itu relatif?) dan satu pernyataan (Saya berpikir maka saya ada). Dengan kata lain, frame ketiga menyatakan pertanyaan yang dari jaman ke jaman selalu ditanyakan orang (terutama ketika mereka berbicara tentang filosofi atau apapun namanya di jamanjaman tersebut). Mengenai hal itu sudah diurai di sub bab yang mengurai tentang makna awal filosofi.

Adapun mengenai pernyataan 'Saya berpikir maka saya ada' pada frame pertama ini, kita bisa berbicara banyak tentangnya. Bisa saja kita mengatakan bahwa esensi semua pertanyaan dalam filosofi -atau bahkan dalam kehidupan- adalah berpikir. Berpikir tentulah seperti kata Bergson bukan cuma dilakukan mahluk yang bernama manusia. Amuba tidak mempunyai organ perut, tapi kita yakin dia makan. Implikasinya: amuba juga tidak mempunyai organ otak, tapi setidaknya kita dapat simpulkan bahwa dia berpikir. Tingkat berpikir tinggilah yang membedakan manusia dari mahluk lainnya. Setidaknya begitulah dalam perspektif Islami -atau mungkin perspektif manusiawi (homo sapiens, mahluk bijak) umumnya- sehingga manusia ditunjuk menjadi khalifah atau pemimpin di muka bumi ini.

Sampai pada uraian demikian ungkapan Cartesian 'Saya berpikir maka saya ada' nampak tidak bermasalah. Atau, malah memberi suatu penguatan pada atau selaras dengan perspektif Islami atau manusiawi. Tapi, seperti disimbolkan oleh frame kedua, philosophy bites, terhadap ungkapan itu kita dapat ajukan tafsir lain. Dalam frame philosophy bites, kita lihat gambar dapat seperti bebek atau seperti kelinci! Dapatkah Anda melihat dan membedakannya? Seperti simbol philosophy bites, ungkapan dapat bermakna lain yang diantaranya bahkan mungkin bertentangan dengan tafsir pertama yang relijius dan manusiawi. 
Tafsir humoris berupa I stink therefore I am (saya bau alami maka saya ada, parodi Cartesian I think therefore I am, saya berpikir maka saya ada) tidak banyak memberi makna lain selain menunjukkan kreativitas berpikir dan kenyataan bahwa filosofi tentu ada di setiap jaman, termasuk di jaman batu sekali pun. Tafsir lain yang bertentangan dengan tafsir relijius-manusiawi adalah ketika ungkapan 'Saya berpikir maka saya ada' dianggap tidak lengkap serta dilengkapkan menjadi 'Saya berpikir maka adalah Tuhan itu sendiri yang menciptakan atau membuat saya ada'!

Lantas, tafsir mana yang akan Anda pilih, tentulah tergantung pada keputusan Anda sendiri. Termasuk, ketika anda melihat frame keempat pada Gambar 1, ketika dikatakan bahwa studi lapangan dalam bidang filosofoi itu ternyata segersang tanah antah berantah yang letaknya entah di mana, tapi tetap saja dapat dikatakan alam atau nature yang dari kita peroleh nama filosofi alam, filosofi sains atau, terutama di Indonesia, filosofi. Atau sebenarnya, sasaran studi lapangan filosofi (ilmu) berupa alam atau nature itu sebenarnya salah sasaran, karena lapangan itu lapangan klasik pra-Socrates. Lapangan seharusnya adalah bagian alam atau nature yang paling mulia, yaitu manusia yang hatinya saja konon tidak terselami oleh manusia lainnya. Apalagi tentang manusia yang hidup di dunia urban dengan latar lingkungan fisikal yang didominasi beton, manusia telanjang memperlihatkan sifat alami mendasarnya: serakah, pemarah, penghujat, dan lain-lain, sekali pun ada pula sebagian yang berjiwa malaikat.

Berikut adalah contoh kontroversi 'tafsir' di dunia ilmu yang relatif mudah diselesaikan (yaitu dengan syarat Anda menerima prinsip komplementer yang menjadi dasar utama teori kuantum yang diulas di awal tulisan), 'Sejak jaman Newton dan Huygen di abad 17, sudah terdapat dua teori tentang hakekat cahaya. Teori Newton menyatakan cahaya terdiri atas arus partikel sangat kecil... sementara teori Huygen menyatakan cahaya terdiri atas sejumlah gelombang-gelombang kecil... di abad 18, teori Newton Berjaya, sementara di abad 19 teori Huygen yang berjaya (Whitehead, 1957). Sementara itu, contoh kontroversi yang relatif sulit dikompromikan adalah ketika Galileo menyatakan "bumi yang bergerak dan matahari yang diam", kaum inkuisisi menyatakan sebaliknya, yaitu "matahari yang bergerak dan bumi yang diam", sementara teori Newton menyatakan bumi dan matahari dua-duanya bergerak'. Dikatakan kontroversi terakhir ini sulit dikompromikan ialah karena dalam teori Einstein dengan ruang melengkungnya kita lebih sulit lagi membayangkan bagaimana keadaan gerak (termasuk gerak bumi dan matahari) di alam serba melengkung tersebut? Lebih dari itu, kita jadi bertanya: benarkah yang dikatakan Russell (1957) bahwa teori kuantum itu lebih revolusioner dibanding teori relativitas?

Akhirnya, sebagai refleksi mendalam dalam dunia yang lebih masuk lagi, yaitu di dunia filosofi, kita bertanya: apakah semua yang telah kita bahas dalam artikel ini terlalu mekanistismaterialis atau tidak manusiawi? Ketika di tahun 1770-an muncul buku penulis Perancis Holbach yang mekanistis-materialis dengan judul System of Nature, kalangan terpelajar Jerman menanggapinya dengan dingin. Reaksi dan pandangan Goethe berikut mungkin mewakili sikap kalangan terpelajar Jerman saat itu,

"Tidak seorang pun dari kita yang sampai selesai membacanya ... karena harapan kita dikecewakan. Dengan pembahasan system of nature, kita berharap belajar sesuatu tentang alam ... Tapi, betapa hampanya kita rasakan, bumi dengan segala imagenya dan langit dengan segenap bintangnya lenyap. Gerak materi dikatakan abadi dan gerak tersebut, kiri-kanan dan ke semua arah, tidak kurang tidak lebih menghasilkan fenomena keberadaan yang tiada terhingga ... Kita tentu mengaku bahwa kita tidak dapat lepas dari perlunya siang dan malam, musim, pengaruh cuaca, 
kondisi fisikal dan hewani: hanya saja kita merasakan di dalam diri sesuatu yang nampak seperti kebebasan sempurna dari hasrat (will) serta sesuatu yang menghalang-halangi hasrat tersebut" (Mason, 1962: 349).

\section{PENUTUP}

Secara umum, segala sesuatu yang berlebihan termasuk dalam berfilosofi atau mencari pengetahuan pasti membawa efek yang tidak menyenangkan. Dalam artikel ini diurai makna awal dan lanjut tentang filosofi di dunia kontemporer dan di dunia akademis. Sebenarnya dari makna awal dan lanjut tersebut belum benar tergambar atau terurai dengan jelas mana sisi ontologis, epistemologis dan aksiologis dari filosofi. Untuk menguraikan itu semua, diperlukan sebuah kajian lebih lanjut. Dengan kata lain, artikel ini merupakan pengantar untuk melihat filosofi secara lebih utuh lagi, yaitu melihatnya dari sisi ontologis, epistemologis dan aksiologis.

\section{REFERENSI}

Gardner, M. (1957). Great Essay in Science. New York: Pocket Book Inc.

http://www.google.co.id/images?hl=id\&biw=1179\&bih=563\&gbv=2\&tbs=isch\%3A1\&sa=1\&q=philosop hy\&btnG=Telusuri\&aq=f\&aqi=g2\&aql=\&oq=

http://www.google.co.id/images?hl=id\&biw=1179\&bih=563\&gbv=2\&tbs=isch\%3A1\&sa=1\&q=philosop hy\&btnG=Telusuri\&aq=f\&aqi=g2\&aq $=\& o q=$,

http://www.google.co.id/images?hl=id\&biw=1179\&bih=563\&gbv=2\&tbs=isch\%3A1\&sa=1\&q=fisika+ku antum\&btnG=Telusuri\&aq=f\&aqi $=g 1 \& a q \mid=\& o q=$

http://www.google.co.id/images?hl=id\&client=firefox-a\&rls=org.mozilla\%3Aen

GB\%3Aofficial\&biw=1152\&bih=674\&gbv=2\&tbm=isch\&sa=1\&q=accountability\&aq=4\&aqi=g1 $0 \& a q \mid=\& o q=a c c o u n t$

Huxley, T.H. (1957). Science and Culture, dalam Gardner, M. (1957), Great Essay in Science. New York: Pocket Book Inc.

Mason, S. F. (1962). A history of the sciences. New York: Collier Books.

Russell, B. (1957). The greatness of albert einstein, dalam Gardner, M. (1957), Great Essay in Science, Pocket Book Inc., NY.

Russell, B. (1957). The science to save us from science, dalam Gardner, M. (1957), Great Essay in Science. New York: Pocket Book Inc.

Solomon, R.C. (1988). Continental philosophy since 1750: The rise and fall of the self. New York: Oxford Univ Press.

Whitehead, A.N. (1957). Religion and science, dalam Gardner, M. (1957), Great Essay in Science. New York: Pocket Book Inc. 